Chapman University

Chapman University Digital Commons

Pharmacy Faculty Articles and Research

School of Pharmacy

$12-2011$

\title{
Extrapolating Strategies for the Scientific and Technological Development of Underdeveloped Societies from the Examples of South Korea, Slovenia and Serbia
}

Vuk Uskoković

Chapman University, uskokovi@chapman.edu

Dragan Uskoković

Serbian Academy of Sciences and Arts

Follow this and additional works at: http://digitalcommons.chapman.edu/pharmacy_articles

Part of the Asian Studies Commons, Eastern European Studies Commons, Other International and Area Studies Commons, Policy Design, Analysis, and Evaluation Commons, Policy History, Theory, and Methods Commons, $\underline{\text { Science and Technology Policy Commons, and the Science and }}$ Technology Studies Commons

\section{Recommended Citation}

USKOKOVIĆ, V., \& USKOKOVIĆ, D. P. (2011). Extrapolating strategies for the scientific and technological development of underdeveloped societies from the examples of South Korea, Slovenia and Serbia. International Journal of Technology Management \& Sustainable Development, 10(2), 125-145. https://doi.org/10.1386/tmsd.10.2.125_1 


\section{Extrapolating Strategies for the Scientific and Technological Development of Underdeveloped Societies from the Examples of South Korea, Slovenia and Serbia}

Comments

This is a pre-copy-editing, author-produced PDF of an article accepted for publication in International Journal of Technology Management \& Sustainable Development, volume 10, issue 2, in 2011 following peer review. The definitive publisher-authenticated version is available online at DOI: $10.1386 / \mathrm{tmsd} \cdot 10.2 .125 \_1$.

\section{Copyright}

Intellect 


\title{
Extrapolating Strategies for the Scientific and Technological Development of Underdeveloped Societies from the Examples of South Korea, Slovenia and Serbia
}

\author{
Vuk Uskoković ${ }^{1}$, Dragan P. Uskoković ${ }^{2}$ \\ ${ }^{1}$ University of California, San Francisco, CA, USA \\ 2 Serbian Academy of Sciences and Arts, Belgrade, Serbia
}

\begin{abstract}
The recent history of scientific excellence of a society could be used as an indicator of its economic, cultural and communal prosperity. In this work, two examples of countries that successfully arose from the remnants of comparative poverty and established themselves as scientifically thriving societies, South Korea and Slovenia, are compared with the case of Serbia, a country that is presumably on the doorsteps of a similarly explosive developmental path. Guidelines for social progress in the direction of greater scientific and social prominence are outlined in the course of the discourse. It is concluded that the ideal model of growth is to be based on parallel progress on the plane of $R \& D$ policies and on the level of excellence of scientific and basic education. The "leapfrog" approach which dictates that the less developed countries should learn from the mistakes committed by the developed ones and thus accelerate their progress and catch up with the latter is invoked as an essential systemic strategy to be adopted. Incorporation into global scientific network of cooperation is also outlined as a necessity as much as stable and thriving local scientific and technological bases that would make up for prolific grounds for an efficient transfer and implementation of knowledge.
\end{abstract}

\section{Introduction}

\begin{abstract}
"There is something within me that might be illusion as it is often case with young delighted people, but if I would be fortunate to achieve some of my ideals, it would be on the behalf of the whole of humanity. If those hopes would become fulfilled, the most exciting thought would be that it is a deed of a Serb”
\end{abstract}

Nikola Tesla, Address at the Belgrade Train Station

June 1, 1892

The recent history of scientific excellence of a society could be used as an indicator of its economic, cultural and communal prosperity. In his keynote address to the US National Academy of Sciences on April 28, 2009, The US President, Barrack Obama said that "science is more essential to our prosperity, our security, our health, our

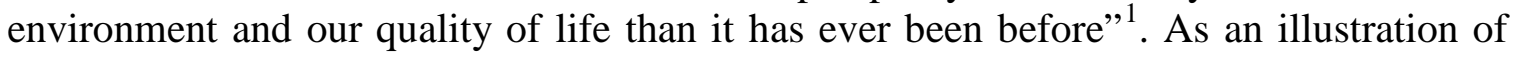
this presupposed direct proportionality between scientific excellence and social prosperity, Fig. 1 shows a continual rise in the science and engineering occupation share of total civilian employment in the US. On the other hand, we seem to live in a world in 
which inequalities and ill distribution of wealth present some of the crucial social factors of its instability and non-sustainability. To illustrate this, Fig.2 demonstrates a disparity between rich and poor countries of the world in terms of many parameters, including the share in world Gross Domestic Product (GDP), export of goods and services, foreign direct investments, and the number of Internet users. Thus, in early 2011 the World Heritage Committee officially recognized the gap between rich and poor as the "Eighth Wonder of the World", describing the global wealth divide as the "most colossal and enduring of mankind's creations". Yet, globalized science of the modern day is a great invitation for cooperation between the rich and the poor. Since the latter stands for one of the most adverse effects that threaten the sustainability of our civilization, equilibration of technological prospects all across the planet can be seen as a vital aim in front of the current generation of scientists. The aim of this paper is to provide insights on factors that could be manipulated with in scientific and social management that ameliorates the problem of pervasive social inequalities and establishes grounds for a lasting and locally supportive scientific productivity within less developed regions and countries of the world. Correspondingly, two cases of advantageous scientific management, i.e., of South Korea and Slovenia, will be presented with the aim of finding the principles that would assist us in outlining the convenient policies and directions of progress for the developing countries, a single example of which is taken to be Serbia.

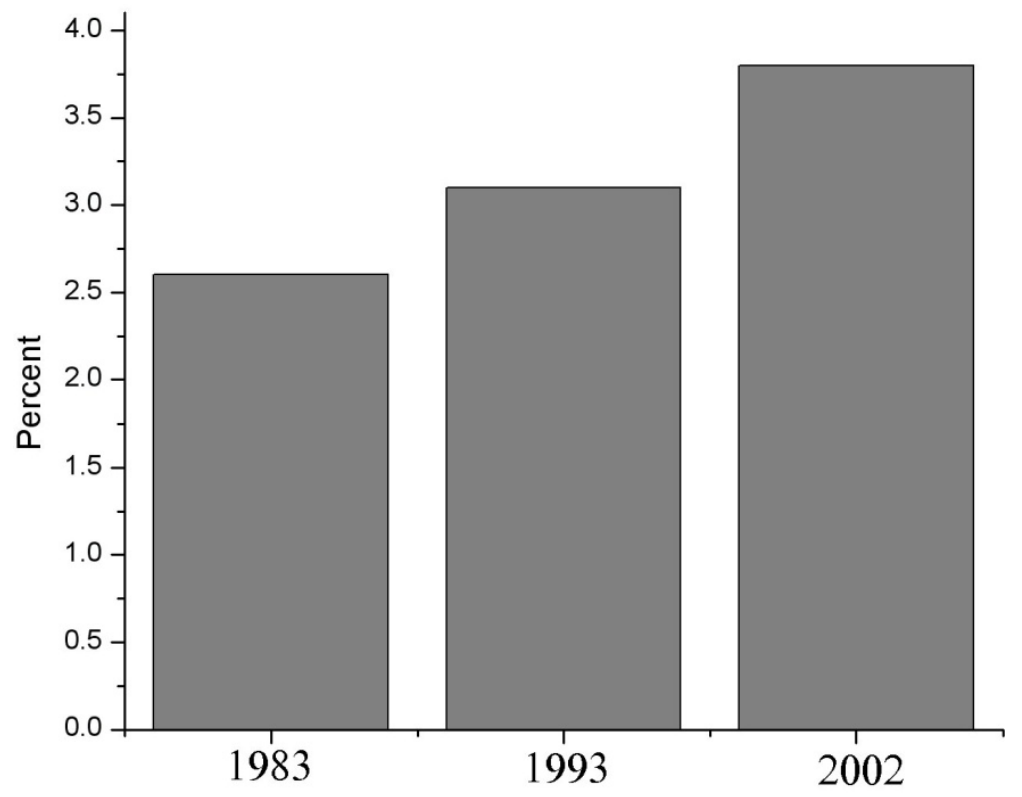

Fig.1. Science and engineering occupation share of total civilian employment in the US in 1983, 1993, and 2002. Source: Science \& Engineering Indicators - 2004, National Science Foundation of the US. 


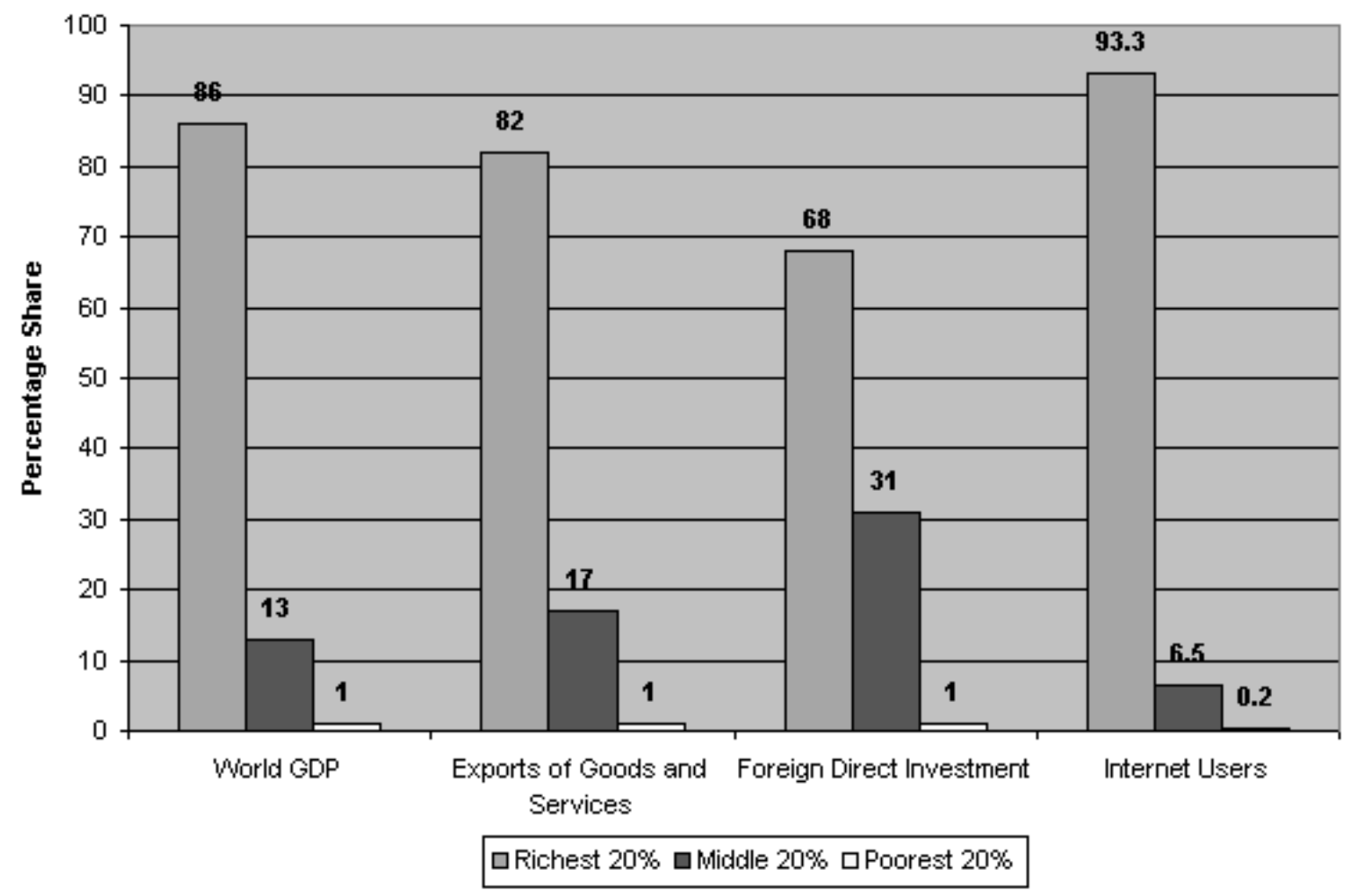

Fig.2. The disparity between rich and poor countries of the world in terms of the share in world GDP, exports of goods and services, foreign direct investments, and the number of Internet users. Source: United Nations Development Program, Human Development Report 1999.

\section{The example of South Korea}

South Korea gives an outstanding example of how only a few decades of wise scientific management and creative labor can be sufficient to elevate a society from relative poverty to global prominence ${ }^{2}$. After it had explosively reached an exceptional level of industrial and technological development in the 1960s, South Korea decided to heavily contribute to scientific research of both applied and fundamental origins, which eventually paid off. As such, the country can be said to have lived up to the starting hypothesis of this discourse, which is that not a single country succeeded in creating a truly prominent and prospective society and culture without investing in scientific R\&D. Among other steps that have contributed to the subsequent impressive expansion of productive academic and industrial R\&D in South Korea, the following ones were taken.

In 1967, a special governmental agency with the purpose of attracting outstanding Korean scientists from abroad was formed which resulted in an influx of foreigneducated researchers and lecturers to South Korean universities as faculty members. Exceptional employment opportunities were provided for academic degree holders, which served as a powerful attractor of young people to higher educational institutions: more than $80 \%$ of high-school graduates currently decide to enroll in one of the universities. What is more, the merits of graduate education were emphasized in response to an increased demand for skilled scientists from private industrial sectors, which 
resulted in enhanced research capabilities at the academic level as well. In order to address the problems of low funding of graduate students, the Ministry of Education launched the "Brain Korea 21" program in 1999, which provided monthly salaries to graduate students ${ }^{3}$. One of the mechanisms to attract students to graduate studies was carried out in concert with the efforts from the Ministry of Defense, which assisted by waiving the otherwise compulsory military duty for all students admitted to any of the graduate schools. This approach highlights the necessity of the cooperative action of several non-associated governmental sectors in implementing a comprehensive plan for scientific development in reality.

However, each progressive run leaves a set of undesired side effects behind itself, which provide opportunities for further research and growth, and South Korean scientific society has not been an exception to this rule by any means. One of them belongs to strong incentives to publish in order to secure stable academic positions, so that the sheer number of scientific publications is often more valued than their quality and impact. Thereupon, the scientists usually do not hesitate to publish their works prematurely and the citation frequency of South Korean researchers consequently does not possess a level as high as the number of publications in comparison with other scientific powers of the world. On the other hand, a recent study has shown that among exceptionally cited authors, South Korea still holds the world share of 31.5 percent, occupying second place, right after the US with 37.6 percent and ahead of the UK with 13.0 percent at the third position ${ }^{4}$. In defense of rapid publishing, however, it can be argued that science develops incrementally and that the timely feedback from scientific society is an important driving force for successful research. It is, therefore, essential to find the right time to publish, and thus avoid both premature announcements of the attained results and retardation of the progress of the field by their prolonged concealment. In order to succeed in that, one is apparently obliged to moderate an attitude that fosters competitiveness between individual research groups by seeing scientific achievements as products of the scientific society and human race as a whole. After all, the very fact that each scientific paper cites other people's works implicitly highlights the influence of other ideas on the author's achievements ${ }^{5}$, implying that the boundary between those who deserve the credit for the given discoveries and those who will be put aside will always be arbitrarily drawn ${ }^{6}$.

The disparity between quantity and quality seems to be a common fate of any evaluation of progress. However, many questions could be raised regarding the validity of single-parameter models, which are intensively used to day and yet hardly provide a good basis for estimating the quality of the evaluated patterns of growth. In that sense, International Scientific Institute (ISI) impact factors, Hirsch and other citation indices, market indices or GDP can be said to present unreliable indicators of quality per $\mathrm{se}^{7,8}$. In order to improve their reliability, these parameters should be incorporated into multiparametric relationships and models of eventually higher complexity. The weakness of using GDP as an indicator of economic wellbeing is reflected in the fact that it does not account for non-market outputs; neglects the preexisting wealth; includes some negative contributions, such as military expenditures and projects that result in environmental deterioration; and, finally, takes no account of social inequality". "Trying to run a complex society on a single indicator... is like trying to fly a 747 with only one gauge on the instrument panel"10, says the evolutionary economist, Hazel Henderson, in this context. Still, eliminating the disparity between quantitative and qualitative insights, 
which currently could be attributed to every type of progress assessment, presents an incessant challenge for the future science analysts and policy makers ${ }^{11,12}$.

Another presumably unfavorable consequence of the South Korean scientific progress has been placing too much emphasis on applied research and too little on the fundamental. The extent of Korean emphasis on industrial research may be best illustrated by the fact that patenting of scientific inventions is so intensively encouraged that South Korea currently holds No. 1 spot in the world in terms of the number of patents per $\mathrm{GDP}^{13}$. On the other hand, only $10 \%$ of all grant applications in basic sciences are approved, with the overall spending also at around $10 \%$ of the total government R\&D budget. Furthermore, the government share in research investments is $25 \%$, which lowers the overall basic research funds to $2.5 \%$ of the total. In view of this, one should be reminded that the most important advents in the history of science, including the major discoveries of quantum mechanics, theory of relativity and molecular biology in the $20^{\text {th }}$ century, were derived neither from market needs, external demands nor preconceived techno-scientific objectives. In fact, it has recently been argued that most of the major scientific breakthroughs in the history of science have evolved from very little or even no funding at all ${ }^{14}$. Although universities are nowadays increasingly under pressure to make ascertain that their research outputs could be commercialized and although research projects with a higher chance of commercialization are often openly preferred in the funding selection processes, too much focus on creating spin-offs without a careful prior analysis of their true potentials could be detrimental for the overall research quality ${ }^{15}$. As Nobel Laureate Leon M. Lederman claimed, "Investments in abstract scientific research, which in industrial societies deduct less that one percent of the budget, pay off much more than any type of asset on Dow Jones market index. Despite that, some baffled politicians occasionally terrorize us by wanting that all science serves only the immediate needs of the society...they have forgotten that the majority of great advancements in technology came from pure, fundamental research, whose main

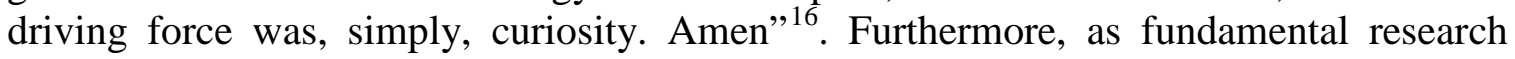
could be considered as the substratum of the applied one, the results of the former often lead to unpredictable ways of utilizing them in various functional devices. The case of quantum mechanics, which was decades after its invention first used in the design of semiconductors and other microelectronic components, offers one such example, while it similarly took decades before the discoveries of molecular biology could be applied for various biotechnological purposes. In fact, the dependence of scientists on nongovernmental investments is a relatively new phenomenon. Individual academic researchers were in most respects free from external directions until the beginning of 1970s. Yet, it is worth noting that a trend of continual increase in R\&D investments coinciding with the continual decrease in global per capita economic growth for the past 30 years has occurred afterwards ${ }^{17}$.

Communication between departments within a single South Korean research institution is typically low, and they mostly function in isolation from each other, which is said to present an obstacle for multidisciplinary research efforts. In this context, one should be reminded that one of the major reasons behind the successful research activity of Rockefeller University - recently announced as the institution from which the largest number of major scientific breakthroughs have originated ${ }^{18}$ - lies in the fact that it is not divided to individual departments, especially for the sake of promoting a fruitful 
multidisciplinary communication. The lack of technical and administrative support is another consequent problem in South Korean scientific organizations, which often leaves scientist alone in attempts to solve them. Doing research in isolation could be convenient while it increases the capabilities for specialized research, but becomes detrimental when complementary knowledge is required to solve the problems faced by single know-how perspectives.

\section{The example of Slovenia}

Slovenia is a member of European Union (EU) with one of the most impressive combinations of GDP, life standard, economic prosperity and scientific productivity. Its current growth rate in technological performance is above the EU average and it is the only accession country that spent more than $1.5 \%$ of its GDP on research and development in 2001 as well as the only one that produced more than 415 publications per million inhabitants ${ }^{19}$. It used to be a republic of the former Yugoslavia, which it seceded from in 1991, and despite the fact that the shrinkage of the local market that followed the collapse of Yugoslav constitution forced many industries to undergo restructuring, downsizing or even bankruptcy, thereby diminishing or even completely eliminating the opportunities for industrial research, proper revitalization incentives from the government level and an openness of academic research to cooperation with industry enabled an ascending trend in many R\&D aspects.

In Slovenia, the promotion of academic research links with various national and international industries has been seen as the most important incentive for scientific productivity and technological success ${ }^{20}$. To exemplify the latter, a single department within Jožef Stefan Institute in Ljubljana, the Department of Advanced Materials, with less than 20 employees, has maintained a persistent cooperation with a dozen of different national and international industries in the past decade. Among business corporations, smart innovation policies resulted in making the public company Gorenje become one of the eight largest European manufacturers of white goods with a $4 \%$ share of the European market in 2006. In 2004, as part of the efforts to extend its links to R\&D domain, it contributed as one of the industrial cofounders of Jožef Stefan International Postgraduate School. In as early as 1985, with the support from governmental and academic institutions Slovenia launched the "2000 young researchers” program aimed to promote postgraduate studies in science and engineering and form a thriving research basis that would satisfy both academic and industrial needs. Furthermore, to improve the ratio of industrial versus academic doctoral degrees (only $20 \%$ in 1995), the Ministry of Science and Technology decided in 1995 to subsidize the salaries for the first three years of newly employed scientists with master and doctoral degrees in industrial research departments. Other legislative incentives, including the law on supporting business enterprises in technological development, were delivered with the purpose of increasing the employment of R\&D personnel and strengthen their research potentials. Assuming that public knowledge institutions are usually not the main source of successful innovations, Centers of Excellence were established at major academic research institutions aiming to integrate basic research with the stages of prototyping, testing and production in selected cooperating companies. Centers like this were imagined to possess a role similar to the one that Japan's largest public research organization, the National 
Institute of Advanced Industrial Science and Technology, has in constructing the bridges that promote transition of research accomplishments to the market. As a consequence of its highly interdisciplinary nature that involves the aspects of administrative support, financial and human resources, networking partners for commercialization and manufacturing, in-depth market analysis, evaluation of the safety standards and quality assessment, this bridge is often named a "nightmare phase" or a "valley of death",21,22 that need to be successfully crossed in order for R\&D creations to be brought into social, economic and ecological daylight.

However, despite the traditionally developed international and regional scientific cooperation and relationships, Slovenia comprises a comparatively small gross scientific network. Even though it is currently involved in more than a thousand bilateral scientific projects, a small number of Slovenian project coordinators is often quoted as a sign of incapacity to support the development of this solid networked basis for cooperation. It is worth noting that Slovenia protected its national and cultural identity throughout the previous centuries due to preservation of politically humble and self-contained attitudes with respect to their neighbors. The extent to which Slovenia succeeded in this is best illustrated by the fact that Slovene is nowadays the only Slavic language in addition to Sorbian that still comprises the dual grammatical number of Proto-Indo-European, even though it has been surrounded by three different linguistic families. However, the questions on future prospects of the impressive economic growth of Slovenia - so far still provided more by large infrastructural investments and less by the targeted development of "knowledge-based" products - are often raised in view of more open scientific, social and immigration policies adopted by the majority of other EU countries. Due to its small size, decisions to rely on its own resources alone would hardly be able to lead to sustainable, sufficiently prominent and internationally competitive research organizations. Small market size also naturally limits the efficiency of translation of research findings into the commercial domain. With only 2 million citizens, Slovenia comprises a small corresponding number of researchers, and as much as the small size of Slovenian research and innovation system could be potentially reflected in uncomplicated and smooth collaboration among scientists and engineers, when it comes to evaluation of research proposals, the demerits of such a small community in which grant approvals could become based on social and scientific prominence rather than on true research capabilities appear as obvious. It is only during the past three years that the practice of an international review of scientific project proposals has been noticed. By promoting conditions for an unbiased competition for research funds, a more efficient expenditure of public funds could be expected. In view of the fact that public tax money has traditionally financed research institutions and still does in large extent, it is necessary to provide the public with possibilities to get acquainted with scientific conduct and key achievements, similar to the function that Japan's RIKEN research organization, old for almost a century, has in increasing public awareness of social phenomena by organizing public lectures, open houses and promoting free newsletters ${ }^{23}$. However, as with all the developing countries in general, one of the central issues that seriously constrain the development rate is the poor implementation of legislative policies. In Slovenia, as a consequence of the comprehensive legislative paperwork done prior to joining the EU, many policies exist "on paper" with the purpose of accelerating the growth of R\&D 
sectors, but their implementation is lagging behind, and evaluations of the effects of different policies are rarely undertaken ${ }^{24}$.

\section{Sets of strategies for the scientific and technological development of underdeveloped societies}

The developing countries should ideally rely on the so-called "leapfrog" strategy in their approach to reach the level of development of rich countries. Accordingly, the underdeveloped countries are invited to learn from the natural cycle of alternating progressions and regressions inevitably present during the growth of a developed country. According to the classical Schumpeter's theory of creative destruction, "the fundamental impulse that sets and keeps the capitalist engine in motion comes from the new consumers' goods, the new methods of production or transportation, the new markets, [a process that] incessantly revolutionizes the economic structure from within, incessantly destroying the old one, incessantly creating a new one" ${ }^{25}$, and it is exactly this unending need to constantly embrace new innovations and discard the obsolete methods that slows down the progressive path of the leaders and gives a chance to the followers to eventually reach the same level of development ${ }^{26}$.

Henceforth, instead of going through the same mistakes that the developed countries have committed, the developing countries would be able to transcend these threats by implementing the right solutions thereto even before they appear imminent in the systems of their own. For example, instead of repeating the same flaws of ecological recklessness that have occurred in the developed world ${ }^{27}$, the less developed countries could timely apply the policies for their prevention, far before the ecological problems become evident locally. It has already been suggested that as technological and scientific development follows a similar sinusoidal path driven by the stages of conception, expectation, hype, saturation, over-hype and backlash, the ability to predict rises and surges of interests in a given idea or technology is crucial in learning how to smoothly ride on these waves ${ }^{28}$. The "leapfrog" tactics in general presents a convenient mechanism for the gradual bridging of large gaps in prosperity that exist between the developed and the underdeveloped societies. In addition, this gap is considered as one of the brakes of an efficient and prosperous globalization in terms of preventing the possibilities for a convenient transfer of know-how and technologies. Implementing policies for its remission is, therefore, crucial for the sustainability of humanity.

Hence, the countries in the developing stages should be fostered to follow the past and current steps of the developed world, and yet to be active and ready to implement actions to prevent their mistakes in due time. Based on economic predispositions and cultural and geographical background, each society requires a unique organization thereof, whilst at the same time a certain level of similarity of the patterns of growth is to be expected among individual societies. However, as of today, the developing countries rarely adopt this strategy. Namely, they either choose to be passive followers of the world leaders and thus in extreme cases become inert slaves of the foreign capital, or decide to isolate themselves from the rest of the world and enforce obsolete and overly centralized ways of social management.

Furthermore, it is an old cliché that teaching people the art of fishing instead of merely handing them the fish that can last only for a few meals is the correct approach to 
helping an impoverished society. In such a way, sustained social welfare is fostered instead of passive servitude. Hence, the ideas that one helps a society by indirectly sending charities and aids thereto should cede its place to an approach permeated with greater amounts of direct and productive communication that provides eligible education for the underdeveloped ones. Similarly, instead of investing in tops of the frequently corrupt governments of the poor countries, the attitude of providing a high-quality education and a fertile ground for the locally sustained economic growth should become more pervasive.

Consequently, the correct pathways of development occur at the intersection of two progressive directions: top-down and bottom-up. Whereas the former corresponds to the management of social relationships by means of convenient policies brought about from centralized hierarchical levels, the latter belongs to improvements of the society at its fundamental organizational levels, including the provision of educational opportunities and the generation of productive academic and industrial bases upon which scientific research and its results would find a fertile ground.

Good education has been many times evidenced as the general basis of social prosperity. When a society is permeated with high-quality education (which includes not only professional trainings, but general knowledge, ethical teaching and upbringing in childhood as well) it can live on through the hard times without reaching the states of civil anarchy, tyranny and corruption. In accordance with the circular causal nature of physical phenomena in general ${ }^{29}$, the attempts to improve the rate of development of a given society in politically hierarchical, 'top-down' fashion become at certain point encountered with puzzling circular causal chains in which each cause presents an effect and vice versa. It can be, thus, noted that in order for the problem of planetary poverty and famine to be solved, stable political and security bases should be set, for which good educational foundations are required, for which the solution of existential poverty becomes the necessary precondition ${ }^{30}$. Or, as a Roma who appeared on a Serbian TV one day wittily noticed, "Gypsies are poor because they do not go to school, and they do not go to school because they are poor and nobody expects them to go to school, which makes it a vicious circle of a kind". Hence, "there is no formula for social and cultural change; puzzling out which came first resembles the problem of chicken and egg"31, as the environmental activist, Brian Tokar, pointed out.

The true meaning of the grassroots concept corresponds to idea that the social and scientific prosperity has to be built from its foundations. The essence of grassroots approach is connected to bottom-up incentives and design and since ecological movement bloomed owing to grassroots approach, so should we be sure that creative people in developing countries should be encouraged to get involved locally and devise steps towards more sustainable society rather than wait for top-down, legislative incentives. Sustainable organization of the society on the basis of ecological principles and deep ethical engagements on the professional plan should, therefore, present an allpervasive support of social creations.

Applied research is, as the name itself suggests, most productive when it is carried out on the basis of already established infrastructural and industrial prosperity. The first stage in the example of South Korean development corresponded to technological and industrial improvements. Only then were the steps to increase the scientific productivity made. On the other hand, the success of fundamental research is nowadays similarly 
inextricably dependent on expensive, high-tech equipment, such as high-resolution electron microscopes, complex telescopes, spectral analyzers, etc. Even though a general consequence of the post-World-War-II division to abundant funding of research in the European West and poor funding in the European East has predisposed the former to become more skillful with experimental techniques and the latter to focus more on developing strong theoretical capabilities ${ }^{32}$, comprehensive theoretical research nowadays frequently requires expensive computational settings. This is, however, not to say that there is no hope for basic research in less developed countries. Quite contrary, the recent breakthroughs in simple and yet extraordinarily efficient synthetic methods based on self-assembly and soft chemistry provide the opportunities for competition of low-cost experimental setups with expensive lithographic techniques, at least when the aspect of synthesis is concerned ${ }^{33,34}$. These unlimited potentials of simple and ecoefficient synthetic procedures present the reason why the Nobel Laureate, George M. Whitesides recently proclaimed that "we are at a wonderful time for chemistry; it is, I believe, in the position of physics in the 1910s, just before quantum mechanics made the world impossibly strange, or biology in the 1950s, just before the double helix obliterated the old biology"35.

To sum up, the only sustainable way to initiate the formation of a successful and productive society lies in the coalescence of smart policies that descend down to society from the top levels of governmental regulations and the promotion of valuable education and professional training that extend from the level of individuals towards society. Only the approach of preserving the cultural basis of the society as much as fostering an openness to information exchange with the rest of the world could be accepted as a correct one in the context of a harmonious globalization. Either the openness to external influences that would erase the invaluable cultural background of the society or the closeness to international communication driven by fears that the national heritage would be deprived thereafter, both present wrong and unbalanced approaches. Yet, as of today, it seems as if the developing countries and particularly those in transition to free market economies are rarely ready to adopt this strategy of balanced openness and closeness. They either decide to be overly open by choosing to be passive followers and imitators of the developed world, which in extreme cases predisposes them to become slaves of the foreign capital, or decide to isolate themselves from the rest of the world and enforce obsolete and overly centralized ways of social management.

The synergistic and balancing attitude expounded herein is consistent with both the nature of perception and biological constitution of human beings ${ }^{36,37,38,39}$. Firstly, the construction of experience proceeds from within the human brain as much as it becomes "drawn" on the basis of the sensual detection of the physical features of the surrounding world. Secondly, biological creatures comprise an inherent balance between operational closeness and thermodynamic openness. Whereas the former contributes to inability to manipulate therewith in the sense that all decisions are eventually brought about from internal sources, the latter accounts for the exchange of matter and energy in which the living creatures need to be constantly engaged in order to maintain their physical structures.

\section{The example of Serbia}


In comparison with South Korea that has continuously raised its scientific and technological performance in the past few decades, Serbia illustrates a country that lived through the opposite path. As the largest republic of the former Yugoslavia, Serbia was involved in the Yugoslav phenomenon of being an excellent bridge for the scientific communication between East and West. Neutral with respect to the Cold War, it used to be one of those rare places in which open-minded American and Russian scientists could meet before the fall of the Iron Curtain to exchange scientific ideas. For example, in the period between 1969 and 1989, Yugoslavia was the permanent host country of Round Table meetings on Sintering, later renamed to World Conferences on Sintering, organized by the International Institute for the Science of Sintering ${ }^{40,41}$. As a founder of the largest union of third-world countries, it also provided possibilities for their successful integration into the promises of the developed world. The Yugoslav system of selfmanagement, designed to bridge the extreme communist and capitalist economies which belonged to the East and the West, respectively, was celebrated all over the world ${ }^{42}$. American experts at the time acknowledged Yugoslav scientists as their most prominent partners in addition to Israeli researchers, while the Yugoslav passport was considered the most expensive one on the black market. However, although it used to be quoted as one of the most original and prospective political systems that the world curiously kept an eye on, it collapsed because of the corruptive influence that the state, the Communist Party and its Central Committee and the labor unions that oversaw the functioning of the workers' councils exerted on the latter. The subsequent breakup that had begun in 1991 with military conflicts, altogether with the persistence of an obsolete and corrupt government despite the innumerable protests of students and members of the intellectual elite, slumped the Serbian life standard straight to the bottom of Europe's ranking.

One of the many positive aspects of Serbian science is comparatively strong and comprehensive education. However, an over-extensive education takes its toll as well. For example, the annual transience rate at the Faculty of Physical Chemistry, one of the most prestigious colleges at Belgrade University has been as low as $10 \%$, whereas the average duration of studies is at 8 years almost twice longer than the anticipated 4.5 years. The educational system is also blamed for its lack of flexibility, as most colleges pursue only general study programs, without offering options to start the specialization in certain fields at an early undergraduate stage. The recent adoption of the study management in accordance with the Bologna declaration is expected to increase flexibility and diversity of the teaching system. However, despite having been enacted a few years ago, the Bologna declaration targets the transience rate of $80 \%$, and yet at the University of Belgrade as a whole, it is currently as low as $16 \%$. In general, only $25 \%$ of high-school graduates enroll in one of the colleges in Serbia, whereby $70 \%$ of the admitted subsequently drop out.

Another major demerit of the college education is that it proceeds in an almost complete isolation from the scientific and technological needs of the society. Nonaccommodation of the study programs to the actual labor market as a result leaves $95 \%$ of fresh graduates unable to find a job without an additional training. Furthermore, there is a consequent disparity between close to a million of unemployed persons and about 50,000 permanently open positions due to a lacking in appropriate qualifications and skills $^{43}$. In Slovenia, for comparison, all students are, prior to graduation, obliged to spend at least six months at one of the external research institutions while being actively 
engaged on the ongoing projects. In many other countries, students are instigated to get involved in research at an early undergraduate stage. However, whereas in Slovenia the students are usually refused an authorship on the resulting publications, in the US, for example, undergraduate students are normally granted the same right, which provides even more incentives for the development of their research skills and interests.

Science is an adventure of human mind, and unless the students are at an early age made aware of this adventurous character of scientific research, their passion for it could easily become exhausted. However, instead of engaging students in projects of actual importance, their professional training typically deals with comprehensive theoretical calculations and laboratory examples without any immediate research significance. Thus, instead of promoting the sense of responsibility with an active involvement of students in the projects of real-life significance, they are suffocated with laboratory practices that possess predetermined outcomes. As a consequence, freshly graduated students have little or no awareness at all how their knowledge could be implemented in the "real world", and are rarely attracted to find a research position in the home country. Instead, the most talented graduates decide to pursue their subsequent studies and professional career abroad. For example, $90 \%$ of the graduates of the Faculty of Electrical Engineering in Belgrade from the period between 1992 and 2000 continued their careers abroad, whereas the general trend estimated among natural science students at Belgrade University is slightly less drastic: $33 \%$ find positions in foreign countries after the graduation. This brings us to the central problem of the so-called "brain drain".

The number of Serbian immigrants in the world is estimated to be more than half a million, a large portion of them being highly educated people that emigrated during the harsh economic era of the past 15 years ${ }^{44}$. In comparison, the majority of Slovenian doctoral scientists after a short-time postdoctoral stay in foreign laboratories decide to return. It is a question at which point the current trend of slow economic progress would start reversing the intensity of "brain drain" phenomenon, the one that heavily damages the local society. However, this phenomenon does not only have negative aspects. In fact, it could provide a crucial impulse in the networking of local R\&D infrastructure with international institutions and associations, and as such could be under certain conditions renamed into "brain gain". There are examples of successful cooperation initiated by the foreign-based scientists, either in form of common research projects, transfers of technologies or expert consultations. Yugoslav Materials Research Society has through its annually held YUCOMAT conferences proven that the professional relationships of the intellectual diaspora in the field of materials science can indeed attract renowned scientists from abroad and provide a space for the exchange of ideas and formation of various types of collaboration ${ }^{45,46,47}$.

One of the strategies for the less developed countries to compete and possibly catch up with the more developed ones is through keeping pace with them at the level of excellence of the fundamental research. YUCOMAT conferences have presented examples of well conducted endeavors to sustain this excellence by stimulating the highest-quality research and connecting local scientists with the research trends that are on the frontier of the contemporary materials science. Other nations have also worked on organizing annual meetings of foreign-based scientific experts with the purpose of including their knowledge in the process of crafting the science policies at the domestic level, and Encuentros conferences conducted with the aim to integrate Chilean 
researchers worldwide into $R \& D$ projects of domestic importance may be one example ${ }^{48}$. Similar associations composed of scientific experts of Serbian origin have existed, with ETF BAFA, an association of electrical engineers working in San Francisco Bay Area, regularly promoting partnerships between foreign-based Serbian investors and domestic technological projects, being one example. Fostering a more official recognition and integration of such small foreign-based islands of experts into science policy making at the domestic scale is thought to be an excellent step forward in this sense. The contemporary electronic communication systems, including various networking platforms, from Facebook to Linkedin to topical internet forums, can, in addition, significantly facilitate the process of seeking potential partnerships. Among other steps that ought to be taken to unfold the positive potentials of the "brain drain" are: (a) enactment of legislations that would stimulate the links between academia and industry; (b) instigation of scientists to engage in common projects at the international and local levels alike; (c) building confidence in the actual economic and social surrounding; and (d) opening the doors for the dialogue on the subject of incorporating the experience and knowledge of scientists abroad into the selected areas of development, essential to prevent early doubts and late dissatisfactions that often exist between the returning migrants and their colleagues at home ${ }^{49}$. It should also be an ethical responsibility of emigrating scientists to conceive and build the bridges between their countries of origin and the countries in which they have settled in, particularly in view of the fact that the public tax money used to pay for almost all high-school and college tuition fees until less than a decade ago. In that sense, one should be reminded of the sententious words of the Slovenian physicist and poet, Jožef Stefan, "Practical field is large, and a lot more is required for the ascent of our men. However, penning so is a daunt task; for that, we need men that have some science in their heads and some love in their hearts" 50 .

Only a spinning windmill can mill the wheat, and any grains thrown into a still mill are predestined to go rotten. The same happens with human knowledge in the deficiency of an intellectual infrastructure within the society. In a country like Serbia, the major problem behind the scientific inefficiency in both research and application domains is associated with an inability of scientific research to find a fertile ground at the local level. This explains why R\&D investments relative to GDP are at $0.5 \%$ extremely low in comparison to other European countries, and to the range of $2-3.5 \%$ in the developed countries in general (Table 2). Furthermore, the absolute amount of investments added up to only 7.5 euros per capita in 2004, which is, however, five times more than 1.5 euros per capita in 2000. Low investments have naturally corresponded to negligible levels of scientific productivity on average. In a five-year period, $2000-2004$, only $25 \%$ of scientists funded by the Ministry of Science had at least one article published in one of the ISI Journals. Furthermore, the average research costs per article were at 33,000 euros by an order of magnitude lower in comparison with the second-wave members of the EU. Although Fig.3 demonstrates that scientific output is the function of the amount of investments, it is a big question whether simple increases in investments in science without a well-coordinated action of other governmental and industrial sectors, and longterm prospects of economic progress, would be a smart solution. On the other hand, as scientific productivity presents a strong indicator of the overall social welfare, placing more emphasis on the significance of science in Serbia would present an inevitable aspect of any progressive policies. 

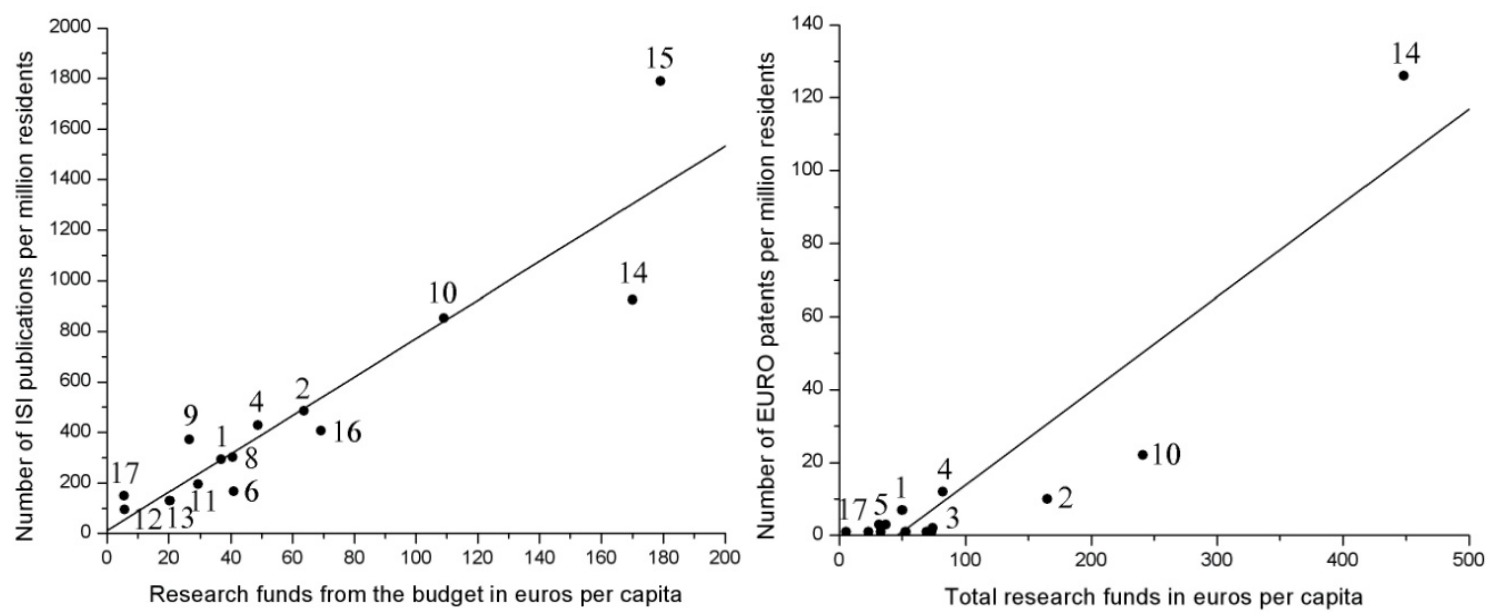

Fig.3. Number of ISI publications per million residents as a function of research funds from the budget in euros per capita (left), and number of EURO patents per million residents as a function of total research funds in euros per capita (right). The assigned country numbers and the corresponding data are from Table 2.

Encouraging smart and competent methods for the allocation of research funds presents another important step. However, corrupt and superficial ways of managing these selection procedures, often dependent on political and social relations or years spent in service rather than on true scientific expertise, are the major difficulty. The general lack of transparency is reflected in the fact that governmental committees are partly involved in the nomination and selection of heads of the research organizations, which similarly to other social domains signifies the importance of fulfilling political interests rather than claiming scientific or other types of professional excellence. In view of the largest concentration of scientists at or around the academic and independent research institutions rather than within industrial research centers, and a devastated high-tech industry in comparison with the Yugoslav era (in fact, some of the first large-scale investments of foreign companies in any of the Eastern European countries occurred in the former Yugoslavia: for example, in the mid-1960s, the Japanese company Murata initiated a cooperation in the field of capacitor ceramics with the Electronic Industry Niš, which at those times also had a regular collaboration with Philips in the research of magnetic ceramics, whereas in the early 1980s the Swedish company Sandvik engaged in common production of cutting tools with the holding company Prvi Partizan), a novel and multidimensional method for financing research is needed. Instigation of strong and diverse education-research-innovation links that would be in favor of a facile achievement and application of research results is equally required. In that sense, small country size presents an advantage in terms of opening possibilities to design simple research and innovation systems, whereby, on the other hand, its disadvantages are mirrored in incessant concerns that resources, both financial and human alike, could be less than optimal for the development of a modern knowledge-based society. 


\begin{tabular}{|c|c|c|c|c|c|c|c|c|c|c|c|c|}
\hline \multirow{2}{*}{$\begin{array}{c}\text { No. } \\
\\
\\
\\
\\
1 \\
\end{array}$} & \multirow{2}{*}{$\begin{array}{l}\text { Country } \\
\text { Cyprus }\end{array}$} & \multirow{2}{*}{\begin{tabular}{c|} 
Population \\
in millions \\
\\
\\
\\
\\
0.8 \\
\end{tabular}} & \multirow{2}{*}{$\begin{array}{c}2001 \text { GDP } \\
\text { per capita } \\
\text { in } 1,000 \\
\text { euros } \\
\\
\\
18.5 \\
\end{array}$} & \multicolumn{2}{|c|}{$\begin{array}{l}\text { Total research funds } \\
\text { and funds from the } \\
\text { budget in \% of GDP }\end{array}$} & \multicolumn{2}{|c|}{$\begin{array}{l}\text { Total research funds } \\
\text { and funds from the } \\
\text { budget per capita (in } \\
\text { euros) }\end{array}$} & \multirow{2}{*}{ 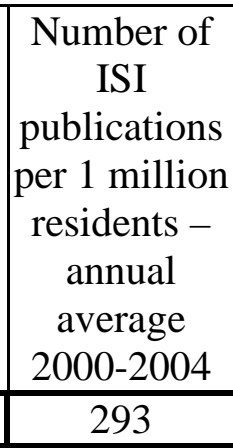 } & \multicolumn{2}{|c|}{$\begin{array}{l}\text { Average costs per single } \\
\text { ISI publication from } \\
\text { total and budget funds } \\
\text { (in } 1,000 \text { euros) }\end{array}$} & \multirow{2}{*}{\begin{tabular}{|c|} 
Number of \\
EURO \\
patents per \\
1 million \\
residents \\
\\
\\
7 \\
\end{tabular}} & \multirow{2}{*}{$\begin{array}{c}\text { High-tech } \\
\text { export out } \\
\text { of total } \\
\text { export (\%) } \\
\\
2.7 \\
\end{array}$} \\
\hline & & & & 0.27 & 0.20 & 49.8 & 36.9 & & 170 & 126 & & \\
\hline 2 & Czech Rep. & 10.2 & 13.3 & 1.24 & 0.48 & 164.7 & 63.7 & 485 & 340 & 132 & 10 & 7.8 \\
\hline 3 & Estonia & 1.3 & 9.8 & 0.75 & - & 73.7 & - & 462 & 159 & - & 2 & 21.7 \\
\hline 4 & Hungary & 10.2 & 11.9 & 0.69 & 0.41 & 82.0 & 48.7 & 429 & 191 & 114 & 12 & 22.9 \\
\hline 5 & Latvia & 2.4 & 7.7 & 0.41 & - & 31.6 & - & 145 & 218 & - & 3 & 2.2 \\
\hline 6 & Lithuania & 3.7 & 8.7 & 0.60 & 0.47 & 52.4 & 41.0 & 166 & 316 & 247 & 1 & 2.7 \\
\hline 7 & Malta & 0.4 & 11.9 & - & - & - & - & 143 & - & - & 5 & 64.4 \\
\hline 8 & Poland & 38.6 & 9.2 & 0.75 & 0.44 & 69.1 & 40.5 & 302 & 229 & 134 & 1 & 3.0 \\
\hline 9 & Slovakia & 5.4 & 11.1 & 0.66 & 0.24 & 73.0 & 26.5 & 373 & 196 & 71 & 1 & 4.1 \\
\hline 10 & Slovenia & 2.0 & 16.0 & 1.51 & 0.68 & 241.1 & 108.6 & 853 & 283 & 127 & 22 & 3.7 \\
\hline 11 & Bulgaria & 8.0 & 6.5 & 0.57 & 0.45 & 37.1 & 29.3 & 195 & 191 & 151 & 3 & 2.3 \\
\hline 12 & Romania & 22.4 & 5.8 & 0.40 & 0.10 & 23.2 & 5.8 & 94 & 246 & 61 & 1 & 4.5 \\
\hline 13 & Turkey & 67.0 & 5.2 & 0.63 & 0.39 & 32.8 & 20.3 & 130 & 253 & 156 & 1 & 4.0 \\
\hline 14 & EU-15 & 377.5 & 23.2 & 1.93 & 0.73 & 447.8 & 169.4 & 924 & 485 & 183 & 126 & 19.7 \\
\hline 15 & Sweden & 8.9 & 23.6 & 3.78 & 0.76 & 891.1 & 179.2 & 1790 & 499 & 100 & - & - \\
\hline 16 & Portugal & 10.0 & 11.0 & 0.76 & 0.63 & 83.4 & 69.2 & 407 & 205 & 170 & - & - \\
\hline 17 & Serbia & 7.5 & 1.4 & $\begin{array}{r}0 \\
(20\end{array}$ & & & $\begin{array}{l}\text { rage } \\
04 \text { ) }\end{array}$ & 150 & 33 & - & $0-1$ & $0-1$ \\
\hline
\end{tabular}

Table 2. Scientific and technological R\&D parameters for different European countries and European Union prior to its expansion in 2004 (EU-15). Sources: Pamphlet on the research in the EU issued by the European Commission in 2003; B. Golob, S\&T Institutions 
and S\&T Policies in the EU Acceding Countries - Challenges for the Development of the Knowledge Based Economy, Institute for Prospective Technological Studies, Brussels, April 2004. 
We have seen in the previous section that technological design and industrial solutions that are demonstrated as successful in the context of a developed society many times turn out to be disastrously impractical and inefficient when simply transformed to less developed social circumstances ${ }^{51}$. As a result, the strategy of adjustment of production capacities to local needs, and on the basis of ecological principles should be promoted instead of the endorsement of massive and largely inert industrial facilities. In that sense, it should be noticed that one of the major obstacles to implementation of intrinsically "green" processing methods is tied to the fact that contemporary chemical industries, based on synthetic methods developed in times when not much attention was paid to their energetic, social and ecological costs, rely on heavy capital and gigantic production capacities, and are consequently inflexible to the introduction of technological innovations ${ }^{52}$. However, just as the evolutionary progress of biological systems has not led to the growth of their elementary units (i.e. cells), but rather to an increased complexity of intracellular metabolic patterns and cellular interactions with the environment, the transition to progressive industry, incessantly open to scientific innovations, should not lead to increase in the size of production facilities and enterprises, but to formation of complex networks between socially adaptable (with regard to facile transfer of technologies and knowledge), efficient and eco-friendly fabrication and service units ${ }^{53}$. Along this line of thought, an example is offered by a Slovakian team of scientists who succeeded in commercializing a nanobiocompositebased electrode for the purpose of in situ analysis of wine components, thus linking nanotechnology with the traditional winemaking in an inexpensive and elegant way ${ }^{54}$. As a result, we can say that original innovations aimed at suiting primarily the local environments and coupled with an openness towards the international transfer of knowledge seems to be a prerequisite for building advanced technological bases, from which innovative and internationally competitive research achievements would spring.

Adjusting the technological performance of a small country to its size and to local needs and capabilities should in ideal case present only an aspect of a wider social plan of sustainable management. Considering the fact that rich countries have based their progress on an overall degradation of the underlying natural capital, the chance of the developing countries to overtake the developed societies in their progressive runs lies exactly in the aspect of an advanced ecological performance. In that sense, Serbia could nowadays learn a lot from Germany and the way in which it transformed its destructive nationalism of the Second World War era into one of the most powerful and influential social and political environmental conservation movements in the world. We cannot afford giving up on hope that a similarly devastating form of nationalism that has been released in parallel with the breakdown of Yugoslavia could be with the right incentives from the international community and appropriate technological and educational policies transformed into a truer and more productive "love of the land". With such an approach of tending one's own garden first, the Berlin Wall of international isolation that has taken an enormous toll on the potentials of intellectuals in Serbia could be finally toppled down. At the same time, there is every reason to expect that opening the doors to fruitful international communication and collaboration on R\&D plan would have an ameliorating effect on local political and social problems that are now, hopefully, only the remains of the faint recent past, which is soon to be transformed into a bright and prosperous era in the development of what is to be a vital part of the European science and economy. 


\section{Conclusion}

By comparing two examples of countries that successfully arose from the remnants of comparative poverty and established themselves as scientifically thriving societies, South Korea and Slovenia, with the case of Serbia, a country that is presumably on the doorsteps of a similarly explosive developmental path, guidelines for social progress in the direction of greater scientific and social prominence were arrived at. Most important of all, it is argued that the ideal model of growth is to be based on parallel progress on the plane of $R \& D$ policies and on the level of excellence of scientific and basic education. The "leapfrog" approach which dictates that the less developed countries should learn from the mistakes committed by the developed ones and thus accelerate their progress and catch up with the latter is invoked as an essential systemic strategy to be adopted. Incorporation into global scientific network of cooperation is also outlined as a necessity as much as stable and thriving local scientific and technological bases that would make up for prolific grounds for an efficient transfer and implementation of knowledge.

Furthermore, the signs of a healthy progress of any given society or natural systems in general are evident in the parallel development of communication between the systemic entities of different organizational complexity on one side, and their increasing diversity on the other. Natural systems in their healthy states are diversified and functionally differentiated as much as unified and well integrated. Once this systemic property of progress is recognized, both rich and poor countries should gain responsibility to promote it at their respective levels of control. The former should primarily reorient towards ensuring not only fair transactions in terms of short-term reciprocities, but primarily long-term sustainable interactions between developed and underdeveloped countries of the world, which would foster the appropriate balance between unity and diversity. The developing countries have the same task, but to be carried out on far smaller plans. And we, individual human beings, in accordance with the tradition of wisdom and ethics of our civilization, are responsible to pay attention to the importance of the invisible roots of science, thought and creativity as much as on the measurable welfare. For in the end, it is profound education that presents the foundations of a sustainable society.

Vuk Uskoković was born in Belgrade, Serbia in 1976. He had obtained a BSc degree from the Faculty of Physical Chemistry at Belgrade University in 2001, and in 2003 was awarded with an MSc degree in Advanced Materials and Technologies from the University of Kragujevac. From 2002 to 2006, he was with the Advanced Materials Department of Jožef Stefan Institute, Ljubljana, Slovenia. He obtained a PhD degree in Nanosciences and Nanotechnologies from Jožef Stefan International Postgraduate School in 2006. From 2006 to 2007 he was working with Victor K. LeMer Prof. emeritus Egon Matijević at the Center for Advanced Materials Processing of Clarkson University, Potsdam, NY. The main topic of his research was the precipitation of cholesterol by the means of colloid chemical methods. From 2007 to 2010 he was with the Department of Preventive and Restorative Dental Sciences at the University of California, San Francisco (UCSF), where he was involved in the research of biomimetic formation of biomineralized tissues. Currently, he is an NIH fellow and a member of the Department of Bioengineering and Therapeutics Sciences at UCSF where he works on development of materials for advanced drug delivery. Besides his dedication to scientific research, he has published books and critical reviews that through systemic perspectives cross-link the 
subjects of science, philosophy, sociology, ethics and aesthetics.

Dragan P. Uskoković was born in Cetinje, Montenegro in 1944. He graduated from the Faculty of Technology and Metallurgy at the University of Belgrade in 1967, which was followed by earning a master's degree in 1971 and a PhD in 1974. From 1968 to 1974 he worked at the Institute for Nuclear Sciences Vinča. From 1974 to the present day he has been with the Institute of Technical Sciences of the Serbian Academy of Sciences and Arts, which he was the director of from 2001 to 2011. He is the Founding President of the Materials Research Society of Serbia. He published more than 200 articles in international periodicals, managed more than 20 research projects in basic and technological research and coordinated several international projects with leading research organizations (MaxPlanck Institute, Kyoto University, the US National Institute of Standards and Technology, etc.). His scientific articles were cited more than 1300 times $(\mathrm{h}$-index $=20)$.

Vuk Uskokovic, PhD

Department of Bioengineering and Therapeutic Sciences

University of California

$17004^{\text {th }}$ Street, San Francisco, CA 94158-2330

phone: +1 (415) 412 - 0233

e-mail: vuk.uskokovic@ucsf.edu

\section{References:}

\footnotetext{
${ }^{1}$ Cunningham, Patrick, 2010: European Union: Measuring Success. In: Issues in Science and Technology 26 (3) <http://www.issues.org/26.3/cunningham.html>.

${ }^{2}$ S-J. Oh - “Academic Research in Korea”, Nature Materials 6, 707 - 709 (2007).

${ }^{3}$ T. Hyeon - "The Path of Chemistry in Korea", Nature Materials 6, 541 - 543 (2007).

${ }^{4}$ Seol, Sung-Soo/Jung-Min Park, 2008: Knowledge sources of innovation studies in Korea: A citation analysis. In: Scientometrics 75 (1): 3-20.

${ }^{5}$ Laband, David N., 1985: An Evaluation of 50 "Ranked" Economics Departments: By Quantity and Quality of Faculty Publications and Graduate Student Placement and Research Success. In: Southern Economic Journal 52 (1): 216-240.

${ }^{6}$ Uskoković, Vuk, 2007: Nanotechnologies: What we do not know. In: Technology in Society 29 (1): 4361.

${ }^{7}$ M. Amin, M. Mabe - “Impact Factors: Use and Abuse”, Perspectives in Publishing 1, 1 - 6 (October 2000).

${ }^{8}$ Randić, Milan, 2009: Citations versus limitations of citations: beyond Hirsch index. In: Scientometrics 80 (3): 809-818.

${ }^{9}$ Capra, Fritjof, 1984: The Turning Point: Science, Society, and the Rising Culture. New York: Bantam.

${ }^{10}$ H. Henderson - "Paradigms of Progress", Berrett-Koehler Publishers, San Francisco, CA (1995).

${ }^{11}$ Najmanovich, Denise, 2002: From Paradigms to Figures of Thought. In: Emergence 4 (1): 85-85.

${ }^{12}$ Capra, Fritjof, 2002: The Hidden Connections: Integrating the Biological, Cognitive, and Social Dimensions of Life into a Science of Sustainability. New York: Doubleday.

${ }^{13}$ Mahlich, Jörg, 2007: Innovation and technology in Korea challenges of a newly advanced economy. New York: Physica-Verlag, Springer.

${ }^{14}$ R. J. Hollingsworth - "High Cognitive Complexity and the Making of Major Scientific Discoveries", in Knowledge, Communication and Creativity, edited by A. Sales and M. Fournier, Sage, London, UK (2007).

${ }^{15}$ Editorial - "The Business of Science”, Nature Materials 5, 921 (2006).

${ }^{16}$ V. Glišin (Interview) - "Non-existent Divisions”, Politika, Belgrade (2004).

${ }^{17}$ D. W. Braben - "Pioneering Research: a Risk Worth Taking”, Wiley \& Sons, New York, NY (2004).
} 
${ }^{18}$ R. J. Hollingsworth - "Institutionalizing Excellence in Biomedical Research: The Case of Rockefeller University”, in Creating a Tradition of Biomedical Research: Contributions to the History of the Rockefeller University pp. 17 - 63, edited by D. H. Stapleton, Rockefeller University Press, New York, NY (2004).

${ }^{19}$ Editorial - “Accepting the East”, Nature Materials 3, 343 (2004).

${ }^{20}$ A. Kornhauser (Editor) - "University-Industry Cooperation: Teaching/Learning Manual - Tempus Phare Joint European Project S-JEP-12106”, University of Ljubljana, Faculty of Natural Sciences and Engineering, International Center for Chemical Studies, Ljubljana (2000).

${ }^{21}$ S. K. Markham - »Moving Technology from Lab to Market«, Research-Technology Management 45 (6) $31-42(2002)$.

${ }^{22}$ M. Komoto - »Green Chemistry for New Business Development«, Journal of Synthetic Organic Chemistry Japan 61 (5) 413 - 418 (2003).

${ }^{23}$ Editorial - "Hidden Treasures”, Nature Materials 6, 319 (2007).

${ }^{24}$ M. Komac - "The Framework for Research and Technology Policies in Small Countries: The Case of Slovenia”, Materials Science Forum 494, 1 - 5 (2005).

${ }^{25}$ Schumpeter, Joseph A., 1962: Capitalism, Socialism, and Democracy. Harper Perennial.

${ }^{26}$ Aghion, Philippe/Peter Howitt, 1992: A Model of Growth through Creative Destruction. In:

Econometrica 60 (2): 323-351.

${ }^{27}$ United Nations Environment Programme - "Millennium Ecosystem Assessment Synthesis Report” (2005).

${ }^{28}$ S. Pearton - "The Shifting Tide of Expectations”, Materials Today 10 (10) 6 (2007).

${ }^{29}$ G. Bateson - "Steps to an Ecology of Mind”, University of Chicago Press, Chicago, IL (1972).

${ }^{30}$ C. W. Churchman - "The Systems Approach”, Dell Publishing, New York, NY (1968).

${ }^{31}$ B. Tokar - "The Green Alternative: Creating an Ecological Future”, R. \& E. Miles, San Pedro, CA (1987).

${ }^{32}$ Editorial - “The Long Way to Integration”, Nature Materials 6, 85 (2007).

${ }^{33}$ Dragan Uskoković, Vuk Uskoković - "Towards Sustainable Planet Earth: Small Steps for Small Countries but Big Ones for Humanity”, Presented at the Science and Technology Forum, Seoul, South Korea (2011).

${ }^{34}$ Dragan Uskoković - "International Cooperation in Advanced Materials and Green Technologies", Presented at the Science and Technology Forum, Seoul, South Korea (2010).

${ }^{35}$ G. M. Whitesides - "Revolutions in Chemistry", Chemical \& Engineering News 12 - 17 (March 26, 2007).

${ }^{36}$ E. von Glasersfeld - "Radical Constructivism: A Way of Knowing and Learning”, RoutledgeFalmer, London (1995).

${ }^{37}$ H. Maturana, F. Varela - “The Tree of Knowledge: The Biological Roots of Human Understanding”, Shambhala, Boston, MA (1987).

${ }^{38}$ L. von Bertalanffy - “General System Theory: Foundations, Development, Applications”, George Braziller, New York, NY (1968).

${ }^{39}$ G. Bateson - "Mind and Nature: A Necessary Unity”, Hampton Press, Cresskill, NJ (1979).

${ }^{40}$ D.P.Uskoković, H.Palmour III, R.M.Spriggs (Editors) - "Science of Sintering: New Directions for Materials Processing and Microstructural Control”, Plenum Press, New York and London (1989).

${ }^{41}$ G.C.Kuczynski, D.P.Uskoković, H.Palmour III, M.M.Ristić (Editors) - "Sintering ‘85”, Plenum Press, New York and London (1987).

${ }^{42}$ Estrin, Saul, 1993: Self-Management: Economic Theory and Yugoslav Practice. Bath, UK: Cambridge University Press.

${ }^{43}$ S. Šekeljić - "Editorial: What Serbia has to Offer to Its Youth”, Student, Belgrade (October 1, 2007).

${ }^{44}$ Source: World Population Policies, released by United Nations Department of Economic and Social Affairs/Population Division (2005).

${ }^{45}$ D.P. Uskoković, S.K. Milonjić, D.I. Raković (Editors) - "Research Trends in Contemporary Materials Science”, Materials Science Forum edition, Trans Tech Publications, Zürich (2007).

${ }^{46}$ D.P. Uskoković - »Advanced Materials and Nanotechnologies Explored at YUCOMAT 2010«, MRS Bulletin 36, 395 (May 2011). 
${ }^{47}$ D.P. Uskoković - “YUCOMAT 2009 Presented Issues from Advanced Materials and Nanotechnologies to Their Most Significant Applications”, MRS Bulletin 35, 87 - 88 (2010).

${ }^{48}$ Encuentros, 2010: Encuentros 2010 - Home, retrieved on May 31, 2010, $<$ http://www.encuentros2010.org/>

${ }^{49}$ V. Grečić - "Mobilization at Distance”, Politika, Belgrade (2007).

${ }^{50}$ L. Čermelj - “Josip Stefan: Life and Acts of a Great Physicist”, Slovenski knjižni zavod, Ljubljana (1950).

${ }^{51}$ E. F. Schumacher - "Small is Beautiful: Economics as if People Mattered", 25 Years Later...with Commentaries edition, Hartley \& Marks, Vancouver (1998).

${ }^{52}$ J. C. Warner, A. S. Cannon, K. M. Dye - "Green Chemistry”, Environmental Impact Assessment Review 24, 775 - 99 (2004).

${ }^{53}$ J. F. Jenck, F. Agterberg, M. J. Droescher - "Products and Processes for a Sustainable Chemical Industry: A Review of Achievements and Prospects”, Green Chemistry 6, 544 - 556 (2004).

${ }^{54}$ J. Tkac, J. Katrlik, P. Szomolanyi, M. Stredansky - “Nanotechnology Gets into Winemaking”, Nano Today 2 (4) 48 (2007). 